\title{
Advanced techniques for preservation, processing and value addition of fruits and vegetables to generate extra income
}

\begin{abstract}
Archana Kumari and $\mathbf{J}$ itendra Singh
Apart from fruits, vegetables play an important role in the balanced diet of human being by providing not only energy rich food but also premise supply of vital protective nutrients like vitamins and minerals. Micronutrient deficiencies have detrimental effects on human health. Nearly 2 billion people worldwide are iron deficient resulting in anaemia in 1.2 billion and more than 600 million people have iodine deficiency disorders. It is estimated that the requirement of vegetables per capita is $240 \mathrm{~g} /$ day but, the availability is only $140 \mathrm{~g} /$ day. Therefore, we shall have to produce more to meet the requirement. The food processing industry ranks fifth in its contribution to value addition but tops the list in terms of employment opportunities with approximately 15 lakhs employed consisting of 19 percent of the total investment in the industrial sector but contributes 18 percent to the GDP. Employment potential in post-harvest and value addition sector is considered to be very high. Every Rs. 1 crore invested in fruits and vegetable processing in the organized sector generates 140 persons per year of employment. Heat is widely used in preservation of food by cooking, microwave heating, blanching, frying, canning, pasteurizing, boiling or heating foods prior to consumption. The thermal processed foods (bottled and canned) are totally sterile. In these processed foods both pathogenic and toxin-producing organisms are destroyed.
\end{abstract}

Key Words : Value addition of fruits, Vegetable, Extra income

How to cite this article : Kumari, Archana and Singh, Jitendra (2018). Advanced techniques for preservation, processing and value addition of fruits and vegetables to generate extra income. Food Sci. Res. J., 9(1): 212-217, DOI : 10.15740/HAS/FSRJ/9.1/212-217. 